\title{
Selvagens e pactos demoníacos. Observações sobre um conto de Wilhelm Raabe
}

\author{
Savages and Demonic Pacts. Observations on a Narrative by Wilhelm Raabe \\ http://dx.doi.org/10.11606/1982-8837203266
}

\author{
Helmut Galle
}

\begin{abstract}
The narrative "Zum wilden Mann" (1874) by Wilhelm Raabe presents the story of a pharmacy in provincial Germany and its owner; Raabe's story obeys the stylistic principles of Poetic Realism, the literary current that dominated the second half of the 19th century in German speaking countries. Despite being located in contemporary reality of the author and his readers, the plot and its main characters show features that refer to the fantastic realm of demonic pacts and wild men. These elements interfere with the realist economic relations between the protagonists, based on loans, interests, and globalized commerce and allude to the inhuman aspects of modern business. Divergent from main cultural practice, Raabe attributes the "savage" and the "diabolic" to the recent "achievements" of civilization which emerge likewise in Germany and in former colonies. The Brazil described by the narrative, instead of being an exotic setting, is just another stage of industrial and commercial processes.
\end{abstract}

Keywords: Wilhelm Raabe; poetic realism; demonic pact; savage

Resumo: A narrativa "Zum wilden Mann" (1874) de Wilhelm Raabe apresenta a história de uma farmácia na província alemã e do seu dono, observando os princípios estilísticos do realismo poético, a tendência literária dominante na segunda metade do século 19 nos países de língua alemã. A despeito da localização no mundo contemporâneo de Raabe e seus leitores, a trama e os protagonistas apresentam traços que remetem à esfera fantástica de pactos demoníacos e homens selvagens. Esses elementos interferem com a esfera realista das relações econômicas entre os protagonistas, baseadas- em empréstimos, juros e o comércio globalizado, e aludem aos aspectos inumanos dos negócios modernos. Divergente da prática cultural geral, Raabe atribui o "selvagem" e o "diabólico" às "conquistas" recentes da civilização que emergem de forma similar na Alemanha e nas antigas colônias. O Brasil traçado pela narrativa, em vez de ser um ambiente exótico, é apenas um outro cenário dos processos industriais e comerciais.

Palavras-chave: Wilhelm Raabe; realismo poético; pacto demoníaco; selvagem

\footnotetext{
${ }^{1}$ Universidade de São Paulo, Faculdade de Filosofia, Letras e Ciências Humanas, Departamento de Letras Modernas, Av. Prof. Luciano Gualberto, 403, São Paulo, SP, 05508-010, Brasil. E-mail: helmut_galle@hotmail.com
} 


\section{Introdução}

É surpreendente que o conto “Zum wilden Mann” (1874) de Wilhelm Raabe (1831-1910) seja praticamente desconhecido no Brasil,porque nele convergem dois temas muito caros aos germanistas brasileiros: o tema do selvagem e o do pactuário, numa história que se expande entre uma província alemã e o Império do Brasil. São condições ideais para que o conto seja a base de reflexões interculturais sobre a maneira como os alemães veem o Brasil e o que acontece na recepção brasileira com essas imagens.

Algumas palavras iniciais sobre Wilhelm Raabe. Para os leitores do Brasil contemporâneo, ele deve ser incógnito por falta completa de traduções. Não há livros do autor na página de Karin Volobuef, ${ }^{2}$ que lista literatura alemã traduzida, e os catálogos da Universidade de São Pauloe dos Institutos Goethe tampouco conhecem sua literatura em português. Existe uma referência a uma tradução do conto, publicada no Rio de Janeiro em $1923,{ }^{3}$ mas no site Estante Virtual não se encontram traços do livro. Raabe foi pouco traduzido (КRовв 2016: 38), e a publicação brasileira justamente desse texto se deve, provavelmente, à sua temática.

Embora o autor nunca tenha chegado a ter uma fama internacional, sua obra de cerca de setentanarrativascontava com um público amplo e fiel na Alemanha. ${ }^{4}$ Muitas vezes, seus textos saíram primeiro numa revista cultural, como na Westermanns Monatshefte, uma prática comum para os autores do século 19, que publicavam na Gartenlaube, na Deutsche Rundschau ou em outras. Raabe figura até hoje no núcleo central do realismo alemão. No seu livro sobre o tema, Georg Lukács (1951) lhe dedicou um grande ensaio ao lado de Fontane e Keller, enaltecendo "a verdade das criações" do autor. ${ }^{5}$ Desde os anos 1960, quando se iniciou a edição das Obras Completas na Braunschweiger Ausgabe, Raabe recebeu cada vez mais atenção da crítica, e, hoje em dia, é um dos realistas

\footnotetext{
${ }^{2}$ Disponível em: <http://volobuef.tripod.com>. Acesso em: 2 jun. 2017.

${ }^{3}$ A referência encontra-se, de acordo com a entrada na wikipedia alemã, na biografia de Wilhelm Raabe, da autoria de Hans Oppermann (1970: 98).Disponível em: 〈https://de.wikipedia.org/wiki/Zum_wilden_Mann>. Acesso em: 2 jun. 2017.

${ }^{4}$ De fato, seus primeiros livros eram verdadeiros bestsellers e, quando sua escrita se tornou mais experimental, depois destes sucessos iniciais, ele continuava a ter uma "comunidade de leitores e admiradores", como observou LUKÁCS (1951: 231).

5 „Die Wahrheit des Gestalteten drückt das Wesen Raabes aus; was er selbst meint, ist nur insofern wichtig, als es diese Wahrheit und ihre Widersprüchlichkeit deutlicher hervorhebt [...]“. (LUKÁCS 1951: 232.)
} 
mais analisados pela germanística. As pesquisas são publicadas sobretudo no Jahrbuch da Sociedade Raabe. Para estafortuna crítica mais recente, Raabe é, na sua "modernidade peculiar” (DETERING 1990: 16), aquele entre os realistas alemães cuja escrita ambígua se aproxima mais à condição metafísica do mundo que surge com o final do século 19 (DOBSTADT 2010: 36), porém, sem poder atravessar “a parede impenetrável entre Realismo Poético e Modernidade Literária" (BASSLER 2015a: 89). Em homenagem ao escritor, se inaugurou o Wilhelm-Raabe-Literaturpreis, com um prêmio de atualmente 30 mil euros outorgado a autores como Rainald Goetz, Katja Lange-Müller, Andreas Maier, Sibylle Lewitscharoff, Christian Kracht, Clemens Setz e Heinz Strunk.

Nas pesquisas recentes sobre o autor, a vertente do pós-colonialismo tem sido a mais produtiva (GöTTSCHE 2016: 293). Na realidade, Raabe nunca saiu da Alemanha, e os cenários da sua obra apresentam um forte tom de regionalismo, sem jamais identificar-se com a chamada "Heimatdichtung" (LuKÁCS 1951: 232). Ao mesmo tempo, muitas das suas personagens foram para territórios além-mar, refletindo uma realidade do século 19, quando mais europeus que nunca emigraram para as Américas ou as colônias em outros continentes, impulsionados pela miséria econômica, a repressão política ou pelo desejo de aventura, o fizeram (OSTERHAMMEL 2009: 235ss, 1290ss). Raabe e outros realistas, como Gottfried Keller, ${ }^{6}$ acompanham esses processos com olhos críticos e os representam nas suas obras. Além dos Estados Unidos, são particularmente a Argentina e o Brasil que recebem as ondas de imigrantes europeus - entre eles os germanofalantes - que participaram substancialmente da etnogênese dessas nações.

Quando, em 1885, a editora Reclam pediu a Raabe um conto para o número 2000 da sua Universal-Bibliothek de clássicos econômicos, Raabe escolheu "Zum wilden Mann”, que ele considerava "um dos seus melhores trabalhos" (PARR 2016: 156). O livrinho foi reeditado inúmeras vezes até hoje pela Reclam e deve ter sido adquirido em 1934 por Anatol Rosenfeld, que o trouxe para o Brasil, fato que pode ser deduzido da inscrição de nome eano na contracapa do exemplar no espólio do crítico que se guarda na biblioteca da USP.

\footnotetext{
${ }^{6}$ O protagonista do romance Martin Salander (1886), de Keller, falido na própria terra, deve "emigrar" para o Brasil duas vezes para recuperar recursos financeiros e depois voltar para a Suíça.
} 
Escrito em Braunschweig em 1873 e publicado no ano seguinte na revista Westermanns Monatshefte, "Zum Wilden Mann” é a primeira das Krähenfelder Geschichten que fazem experimentos com novas formas narrativas (PARR 2005: 275). Segundo GöTTSCHE (2013: 27), trata-se do texto mais analisado de Raabe nos últimos quinzeanos. A narrativa é apresentada por uma instância heterodiegética que, em duas ocasiões, deixa a palavra para que os dois protagonistas, o farmacêutico Philipp Kristeller e o coronel Agostin Agonista, contem, cada um,uma versão do passado e de suas biografias.

\section{Selvagens}

O narrador se aproxima do lugar da história, a farmácia "Zum wilden Mann” no meio de um temporal terrível, conduzindo seu leitor pela mão:

Wir suchen einfach, wie gesagt, vorerst unter Dach zu kommen und eilen rasch die sechs Stufen der Vortreppe hinauf; der Erzähler mit aufgespanntem Schirm von links, der Leser, gleichfalls mit aufgespanntem Schirm, von rechts. Schon hat der Erzähler die Tür hastig geöffnet und zieht sich den atemlosen Leser nach, und schon hat der Wind dem Erzähler den Türgriff wieder aus der Hand gerissen und hinter ihm und dem Leser die Tür zugeschlagen, daß das ganze Haus widerhallt: wir sind darin, in dem Hause sowohl wie in der Geschichte vomwilden Mann! - Daß wir uns in einer Apotheke befinden, merken wir auf der Stelle auch am Geruche (RAABE 1874: 2).

Salta aos olhos a metalepse: o narrador brinca, para um leitor fictício, misturando o nível da ficção como nível da realidade. Esse estilo à moda de Laurence Sterne poderia pertencer também a um Jean Paul, um Machado de Assis ou até a um Italo Calvino. Nós, leitores, somos visita num mundo fictício, num lugar insignificante da província alemã, um verdadeiro "campo de corvos/de gralhas" ("Krähenfeld" - aliás: Raabe (corvo) publicava também sob o nome Jakob Corvinus). A partir dessa periferia vamos observar, com o narrador, como o grande mundo e seu desenvolvimento afetam as vidas mais recolhidas.

No primeiro instante, o nome da farmácia - e o título do conto - parecem ser motivados pela mitologia regional. Devido à origem de Raabe, muitos contos do autor são ambientados na zona montanhosa de Baixa Saxônia, no caso o Harz, conhecido literariamente pelo poema de Goethe ("Harzreise im Winter", 1777) e o relato de viagem de Heine (Die Harzreise, 1824). No pico áspero de 1141 metros, chamado de Brocken ou Blocksberg, reúnem-se, de acordo com as lendas pagãs dos saxões, as bruxas e o diabo para 
festejar a noite de Walpurgis (30 de abril), em tempos pré-históricos uma festa de primavera e de fertilidade. Outras tradições populares dessa região referem-se à figura do Homem Selvagem - Der wilde Mann - justamente o nome do povoado mineiro Wildemann, ao lado do Harz,onde, na lenda, trabalhadores encontraram um homem e uma mulher selvagens, sem fala,perto de uma jazida de prata. Lendas desse tipo eram frequentes nas partes montanhosas na Alemanha e na Suíça desde a Idade Média. O Homem Selvagem geralmente aparece como figura humana, muito forte, cabeluda e nua, não necessariamente malvada, que vive nas selvas, afastado dos homens. ${ }^{7}$ Foi considerado como criatura entre ser humano e animal, embora não apresente traços animalescos além dos cabelos. No contexto cristão, o Homem Selvagem às vezes é demonizado e chamado de "tiufel" (OTT 2002: 120). Semelhante aos anões e gigantes, os Homens Selvagens podem guardar veias de metal precioso ou tesouros escondidos nas montanhas e facilitar o acesso a eles. No século 16, como mostrou Luciana VILLAS BÔAS (2014), a figura do Wilder Mann começa a convergir com a imagem dos "selvagens" (ou seja: povos indígenas) que habitam as terras recém-descobertas e com a figura do homem inocente e natural. Na época de Raabe, elesestão presentes como máscaras no carnaval - assim entram na cena "Mummenschanz", do Fausto $I^{8}$ - e nos brasões de muitas casas aristocrátricas, como nas armas do imperador alemão de 1871.

Mas, no conto de Raabe, a figura do selvagem é duplamente motivada. Por um lado, o nome da farmácia parece referir-se às lendas locais; por outro, ele se relaciona com a personagem que facilitou a compra do empreendimento. Pois na tarde do temporal, o farmacêutico Kristeller se dá conta de que faz exatamente trinta anos que ele abriu sua farmácia e decide convidar três amigos para festejar o jubileu com ele e Dorothea, sua irmã corcunda, responsável pelas tarefas domésticas. Tomando ponche com os amigos do povoado, o pastor Schönlank e o caçador Ulebeule, Kristeller conta como chegou a comprar o estabelecimento. Sendo orfão, sua herança paternal foi desperdiçada pelo curador e ele se formou como farmacêutico com grande dedicação à botânica. Nas

\footnotetext{
${ }^{7}$ Cf. o artigo no Handwörterbuch des deutschen Aberglaubens, v. 9, páginas 968-980, aqui 970. „Das mythische Denken aber hält in den Gestalten den oft bösartigen, drohenden, ja grauenvollen „Wilden“ den Schrecken früherer Zeiten vor dem wilden Wald fest".

8 „RIESEN Die wilden Männer sind s' genannt, / Am Harzgebirge wohlbekannt; /Natürlich nackt in aller Kraft, / Sie kommen sämtlich riesenhaft. / Den Fichtenstamm in rechter Hand / Und um den Leib ein wulstig Band, / Den derbsten Schurz von Zweig und Blatt, / Leibwacht, wie der Papst nicht hat."Fausto II, vv. 58645871 .
} 
florestas, ele se tornou amigo de outro adolescente, chamado August, que evitava a companhia dos homens e tinha conhecimento extraordinário das plantas. Uma vez, Kristeller encontrou esse amigo em desespero, numa rocha mal afamada, a chamada Cadeira de Sangue ou Cadafalso (Blutstuhl). ${ }^{9}$ Dias depois, ele recebeu desse amigo uma carta de despedida e 9.500 táleres que possibilitaram o matrimônio com sua noiva Johanne e a compra da farmácia. A noiva morreu, infelizmente, no dia do casamento. Eleassim foi viverna farmácia com sua irmã, se sustentando através da farmácia e da comercialização de um digestivo de receita própria, o "Kristeller". Gozando de boa reputação pelos habitantes da região ele acumulou, como amador, uma coleção de gravuras e desenhos que passou a ocupar as paredes do salão. Durante todos esses anos, manteve livre uma poltrona de honra para seu benfeitor, pois, seguindo o conselho da noiva, Kristeller considerava o dinheiro do amigo como empréstimo e, embora ele tivesse sumido sem deixar rastros, Kristeller continua aguardando sua volta.

Após a narração da história, chega o terceiro amigo, o médico Dr. Hanff, com um estrangeiro que se apresenta como Dom Agostin Agonista, coronel em serviço do imperador Dom Pedro do Brasil. Ao contar sua história, ele se revela logo como o amigo e benfeitor antigo de Kristeller. Proveniente de uma antiga dinastia de carrascos com o nome autoexplicativo de "Mördling", August Mördling se desesperou quando teve que exercer sua profissão pela primeira vez e decidiu fugir do ofício e da terra, liberando-se também da sua herança sinistra mediante a doação do dinheiro acumulado pelo trabalho dos seus precessores. Tendo embarcado para as Américas e lutado contra um navio de piratas haitianos, August Mördling foi salvo por um negro que lhe prometeu proteção em futuras lutas sempre que fosse invocado. Esse momento foi como uma iniciação à vida de guerreiro e aventureiro, e August se tornou Agostin Agonista. Após vários anos na América Latina ele se tornou soldado na tropa imperial brasileira, onde chegou ao cargo de coronel. Com idade avançada, planejou casar-se com uma viúva rica e voltou à Alemanha para buscar seu amigo Kristeller. A propaganda para o digestivoo ajuda a localizar a farmácia e seu dono.

Nos dias que se seguem aessa noite de celebrações, Agonista faz várias propostas para Kristeller sobre como eles poderiam ir juntos para o Brasil e fazer uma fortuna em negócios; mas, numa conversa com a irmã, fica claro que Agonista, de fato, precisa de

\footnotetext{
${ }^{9}$ No Fausto I, Margarida chama de „Blutstuhl“ o cadafalso no qual ela deve ser executada (v. 4592).
} 
dinheiro para o casamento e que ele chegou para cobrar sua doação de outrora. Kristeller e a irmã conseguem pagar a soma completa com os respectivos juros, vendendo praticamente tudo, mas se recusam a acompanhar o coronel para o Brasil. Agonista se torna o milagre da região, tentando convencer várias pessoas de que eles deveriam emigrar com ele e desaparece poucos dias antes do Natal. Kristeller e a irmã permanecem na farmácia, despojada de todo o inventário, sem árvore natalina e entregues à miséria, porém de ânimo sereno.

Após ouvir a história de Kristeller, o guardaflorestal resume:

Wir wissen jetzt, weshalb sich dreißig Jahre lang keiner von uns in diesen Lehnstuhl da hat setzen dürfen; - wir wissen, in welcher Weise unser Freund Philipp bei uns ankam - wir haben viel gehört von Liebe und Tod, von wilden Männern und alten Geldbriefen, wie nicht jedermann solche von der Post zugeschickt kriegt (RAABE 1874: 21).

Implicitamente, ele relaciona o nome da farmácia à história de August Mördling (KROBB2009: 154) e assim essa personagem, antes da emigração, pode ser identificada com a figura do Homem Selvagem. Nessa primeira parte, a identificação se justifica pelos traços singulares de August Mördling. Alguns estão diretamente relacionados à profissãodo carrasco: ele é, por lei, separado da sociedade e das profissões "honestas"; sua profissão é a matança, embora o faça em execução da ordem judicial. Na configuração da história, ele ainda apresenta algumas características diretamente demoníacas: tem conhecimentos da natureza aparentemente ilimitados; ele aparece e some como se fosse um fantasma; ele habita os lugares desertos, evita as cidades e não é conhecido pelos outros homens da cidade. E, como os Wilde Männer da lenda, ele guarda um tesouro que, milagrosamente, passa a ser usado pela pessoa que se torna seu amigo. Nesta parte, podemos dizer, a personagem realista August Mördling recebe conotações da figura mítica do Wilder Mann.

Mas também depois da emigração, August / Agostin pode ser considerado Homem Selvagem, só que agora já não no contexto da lenda popular alemã. Se, por um lado, ele se manteve fiel à sua missão inicial de carrasco, aceitando agora a violência como sua "natureza", por outro lado, ele se transforma em brasileiro. Para os alemães reunidos no salão de Kristeller ele é exclusivamente o brasileiro e o Coronel Dom Agonista - até sua pronúncia do alemão apresenta um ligeiro sotaque estrangeiro. Sua integração num mundo exótico e a participação na violência dessa sociedade menos pacificada fazem com que a personagem receba novamente conotações de selvagem, mas desta vez as do "selvagem 
Galle, H. - Selvagens e pactos demoníacos

brasileiro". Essa imagem é configurada por relatos como a Warhaftige Historia, de Hans Staden (1557) e implica o canibalismo e outras práticas menos apreciadas em países da civilização europeia. A narrativa evoca tais discursos somente de forma genérica, marcando o coronel como “o estrangeiro", e, na voz de Dorothea, quando esta reflete sobre a oferta de Agonista de criação de uma empresa no Brasil:

$\mathrm{Zu}$ den Pottekudern [Botokuden], seinen neuen Landsleuten, gehe ich für mein Teil nicht mit! Er wäre vielleicht imstande, uns in aller Güte und Zureden mit Haus und Hof mit sich zu schleppen und uns mitten in der Urwildnis hinzusetzen und eine Schnapsfabrik auf meines armen Bruders Namen und Likör zu gründen. Aber er soll mir kommen, der Kehlabschneider, der Scharfrichter, der Menschenschinder, der Henkersknecht. Für alle Freibillette in der Welt geh' ich mit ihm nicht nach seinem Amerika; am Spieße brät er uns doch, wenn er uns drüben hat, und wenn er auch noch so schlau hier am Orte den Gemütlichen, den Vergnügten und den biederen treuherzigen Krieger spielt (RAABE 1874: 40).

Em sua fala aparecem os indígenas primitivos (botocudos), a floresta selvagem, as práticas violentas (degolamento) e o canibalismo. Evidentemente, Dorothea não espera que ela e o irmão sejam "assados no espeto" por Agonista. O que ela percebe claramente são as intenções fraudulentas do pretenso benfeitor e amigo. De fato, Dorothea é uma dessas mulheres argutas que Raabe coloca ao lado dos seus protagonistas sonhadores e idealistas, como observou LUKÁCS (1951: 249). O discurso sobre a selvageria brasileira é usado por ela e pelo narrador para denunciar o aventureiro Agonista como burlador e sanguessuga capitalista.

O próprio coronel não deixa dúvidas de que suas atividades no serviço de Dom Pedro são bastante sangrentas, não no sentido de guerreiros primitivos, mas no sentido da supressão de súditos num regime autoritário:

Wir beide [Kaiser Pedro und ich] haben jetzt manch liebes Jahr das vielfarbige Gesindel in Rio de Janeiro zur Ordnung und Tugend angehalten; er durch regelrecht richtige konstitutionelle Güte, ich durch flache Säbelhiebe und im Notfall durch einen kurzen Galopp, drei Schwadronen hintereinander, rund über das Pack weg. Meine Herren und Sie, liebes Fräulein, Sie werden sicherlich noch einmal erschrecken und mich von der Seite ansehen; aber es ist nicht anders, und bei der Wahrheit soll der Mensch bleiben: wenn ich das Köpfen aufgegeben habe, so habe ich mich desto energischer auf das Hängen gelegt und gefunden, daß es eine viel reinlichere Arbeit ist und seinen Zweck ebensogut erfüllt (RAABE 1874: 28).

A selvageria desse "brasileiro", portanto, consiste no exercício da violência estatal, de nenhuma maneira desconhecida na Europa. O Império Brasileiro e o recém-fundado Império Alemão se assemelham, como observa Florian Krobb (2009: 143s), e a "bondade 
Galle, H. - Selvagens e pactos demoníacos

constitucional" pode ser lida como atributo irônico dos dois príncipes. "Selvagem" não é o primitivo, o indígena, a natureza, o outro: selvagem é a própria civilização europeia, que foi exportada para o Novo Mundo. A recepção muito positiva do coronel pelos habitantes do povoado, particularmente o caçador Ulebeule e o médico Hanff, evidencia que o "selvagem" que acompanha os atos da personagem não provoca nenhum estranhamento: o selvagem é o futuro da Europa, saudado com entusiasmo.

\section{Pactuários}

O tema do pacto demoníaco, até agora, foi tocado apenas tangencialmente. De fato, não acontece nada que se assemelhe ao contrato assinado no livro de Spies, onde Mophostophiles recebe a alma de Johannes Faustus para 24 anos de serviço, fornecendo conhecimento, prazeres sexuais, riquezas e poder para sua vítima. Tampouco há uma aposta, no sentido de Goethe, de que o protagonista permaneça fiel à sua insatisfação até a morte, visando representar a condição do ser humano moderno. Não faltam, porém, alusões ao motivo do pacto: o próprio Kristeller dizao amigo desesperado que ele sacrificaria "sangue e alma" para ajudá-lo, ${ }^{10}$ embora não exija nada em troca; e como se fosse o vencimento de um prazo, no exato dia em que a compra da farmácia faz 30 anos, "a data significante arde em cifras e letras ígneas diante de seus olhos". ${ }^{11} \mathrm{O}$ navio pirata haitiano que ataca a fragata do coronel Agonista se chama "Diablo blanco", e este atribui a si mesmo o título "Mestre Urian", ${ }^{12}$ em alemão um dos apelidos de Satanás. ${ }^{13}$ Agostino, por sua vez, na luta contra os piratas, parece fechar um pacto com um "diabo", ou seja com um dos piratas negros, quando este homem lhe promete proteção em vicissitudes futuras

10 „Ich sagte ihm, daß ich mein Blut und meine Seele dran geben würde, ihm zu helfen [...]“ (RAABE 1874: 12).

${ }^{11}$ „Das bedeutungsvolle Datum brannte wie in feurigen Ziffern und Buchstaben vor seinen Augen [...]“ (RAABE 1874: 5).

${ }^{12}$ „Ja, es fällt mir erst jetzt bei: vom alten Wandsbecker Boten hatte mein Alter das meiste in seiner Natur - er konnte es sicherlich nicht ahnen, welch ein Meister Urian in seinem Söhnchen steckte.“ Na revista de Matthias Claudius, apareceu ainda um poema menos diabólico sobre Urians Reise Reise um die Welt(RAABE 1874: 25).

13 „Die Hexen zu dem Brocken ziehn, / Die Stoppel ist gelb, die Saat ist grün. / Dort sammelt sich der große Hauf, / Herr Urian sitzt oben auf“" (Faust I, 3956-3960). 
sempre que Agostino invocasse seu nome. ${ }^{14}$ Agostino confirma que a oferta foi cumprida e que somente a partir de então ele passou a ser bem tratado pelo mundo. Assim, ele declara que seu "contrato"com o negro está dando certo, mas não diz o que ele mesmo prometeu em troca. Nesse momento, as pessoas reunidas na celebração noturna tomam distância dele, particularmente o pastor e a irmã Dorothea, indício de que as palavras de Agonista são levadas a sério.

Além dessas alusões, o conto configura dois pactos de forma estrutural. ${ }^{15}$ A trama apresenta um adolescente pobre que, de forma "milagrosa", ganha uma fortuna que lhe permite casar e fundar uma empresa própria. O matrimônio é impedido pela morte inesperada da noiva e a empresa é desmantelada após um prazo de trinta anos. O protagonista consegue manter sua integridade moral, renunciando a todas as vantagens implícitas no "contrato" nunca assinado. ${ }^{16} \mathrm{O}$ outro adolescente se recusa, num primeiro momento, mas depois entrega-se por completo a uma vida violenta e egoísta. No segundo caso, mesmo que isso não seja expresso em nenhum momento, o diabólico tornou-se a essência de seu caráter, mascarado por uma superfície honesta e jovial.

\section{Realismo}

As modificações do motivo do pacto se devem, até certo ponto, ao fato de o conto inserir-se na época do realismo, a última tendência histórica da literatura que pode ser considerada hegemônica. Ainda que Raabe evoque reminiscências a Ernst Theodor Amadeus Hoffmann com o círculo noturno onde se contam histórias e se bebe ponche, isso apenas doa um ar fantástico a uma realidade muito séria e amarga da vida de Kristeller. As alusões ao selvagem e ao pacto com o diabo, que atravessam o discurso do conto, configuram um

\footnotetext{
14 „,Das wäre der Teufel!‘ rief der europäische Physikus. / ,Der war es sozusagen auch‘, sprach gelassen der brasilianische Oberst, ,und er klopfte mich auf die Schulter und sagte: ,Ihr gefallt mir, Senhor, und ich meine es gut mit Euch - diesmal kommt Ihr noch mit dem Leben davon; erinnert Euch meiner und ruft mich, wenn Ihr mich braucht; ich stehe immer an Eurem linken Ellbogen. ' - Meine Herrschaften, das Ding verhielt sich wirklich so, und ich habe den Schwarzen jedesmal, wenn ich ihn nötig hatte, gerufen und mich stets wohl dabei gefunden“" (RAABE 1874: 22).

15 A partir da época de Goethe, como mostra Volker Hoffmann (1986), o modelo do pacto é sujeito a modificações secularizadoras. Para o autor, "supremacia de conhecimento e um comportamento espacial descontínuo são indícios seguros para o sedutor diabólico" (HOFFMANN 1986: 479) e a oferta para Kristeller corresponde às tradicionais promessas: "propriedade e erótica".

${ }^{16}$ Sobre as trocas e transposições no conto, cf. PARR 2005; 2016.
} 
segundo código, que desestabiliza o primeiro, o realista. Desestabilização não num sentido autorreferencial, como se Raabe abrisse mão de uma representação "mimética" do mundo. A diegese refere-se à Alemanha e ao Brasil de forma séria e histórica. Mas essa representação mimética dos fatos não é suficiente para abarcar a dimensão da calamidade que está acontecendo no século 19 em nível global. Para transmitir essa dimensão irracional e invisível, Raabe, como Goethe antes dele, recorre a recursos simbólicos do mito e da religião, apesar de sua era secularizada não ser mais crente.

O intuito histórico vem à tona já nas palavas do narrador que se apressa a abrigar a si mesmo e seus amigos "nesta nova história", que ele "trasladou consigo da Confederação Germânica para a Confederação da Alemanha do Norte e daí para o novo Império": 17 são as formações políticas que foram vivenciadas pelo autor e que formam o pano de fundo para as biografias de Kristeller e Agonista.

No mundo habitado por Kristeller e Agonista, as monarquias constitucionais dos dois lados do Atlântico servem-se das armas para garantir a ordem, os carrascos investem seu dinheiro em fundos públicos, empréstimos devem ser pagos com juros e a economia começa a globalizar-se. De volta à Alemanha, Agonista sabe ler e apreciar perfeitamente os balanços da empresa, o "selvagem" é tão alfabetizado em contabilidade como o próprio empresário.

O negócio que Agostino Agonista propõe para o farmacêutico é uma empresa que converte bois em cubo de caldo e os cubos em capital.

Vor einigen Jahren war ich in Fray Bentos und sah mir das dortige Fleischextract-Institut an. Großartig! - sie treiben euch vor den Augen einen Ochsen in die Retorte und liefern ihn euch nach zehn Minuten in eine Büchse concentrirt, die ihr in die Hosentasche steckt - wäre das Weltmeer nicht da, dem ihr euer Erstaunen zurufen könnt, ihr wüßtet nirgends damit hin, Philipp. Und vor vierzehn Tagen war ich bei Liebig in München - annähernd derselbe Geruch und Duft wie bei dir, nur noch ein bißchen metallischer; - Kristeller, da können wir einander gleichfalls gebrauchen - ich liefere dir das Vieh, und du lieferst mir den Extract Philipp, ich gebe dir mein Ehrenwort darauf, in drei Jahren machen wir den Herren zu Fray Bentos eine Concurrenz, die sie zu Thränen rühren soll (RAABE 1874: 35).

Na realidade histórica, a invenção que o grande químico Justus Liebig testou em 1855 na farmácia real de Munique havia começado a ser aplicada desde 1863 em Fray Bentos, no rio Uruguai, com capital europeu e a carne bovinadas pampas. A Lemco (Liebig Extract of

\footnotetext{
${ }^{17},[\ldots .$.$] der Erzähler und die Freunde, welche er aus dem deutschen Bund in den norddeutschen und aus$ diesem in das neue Reich mit sich hinübergenommen hat [...]“ (RAABE 1874: 2).
} 
Galle, H. - Selvagens e pactos demoníacos

Meat Company) forneceu o alimento sintético em grande escala para o mundo inteiro e, ao mesmo tempo, participou no desenvolvimento de um novo meio de comunicação, a estampa colorida (Sammelbild). As imagens da Liebig ocuparam um lugar importante na trivialização da cultura e na divulgação de propaganda colonialista e exotismo.

No conto, Raabe se apresenta como observador crítico dessa onda de globalização econômica que abala tanto as colônias e ex-colônias quanto a sua terra. Nem as regiões mais periféricas com seu folclore tradicional são poupadas da grande transformação industrial e comercial do mundo. Para os vizinhos de Kristeller, sua ruína deve-se a falhas na especulação - uma explicação coerente nos anos 1870, embora não completamente condizente com o desenrolar dos fatos do conto.

$\mathrm{Na}$ realidade, o farmacêutico não pode ser visto como oposto do coronel. Com o empréstimo, ele não apenas comprou a farmácia, mas também lucrou com a comercialização nacional do seu digestivo. Agonista pensa, se poderia dizer, em grande estilo, ao projetar a venda global do produto. Se Kristeller ainda é inventor, produtor e vendedor na mesma pessoa, Agonista sabe se aproveitar da invenção e produção do outro, colocando-se no fim da cadeia produtiva e cobrando o rendimento do capital investido. Em vez de ser pioneiro, ele simplemente copia as ideias dos inovadores, tentando destruí-los por meio da concorrência. Nesse sentido, os dois são selvagens, como afirma Dobstadt:

In Wahrheit sind beide, Agostin und Philipp, auf je eigene Weise 'wilde Männer', insofern sie beide auf je eigene Weise eine der Moderne selbst inhärente Radikalität zur Entfaltung bringen; im Unterschied etwa zu Dorette und den Dörflern, die damit als die eigentlichen Gegenfiguren erkennbar werden (DOBSTADT 2010: 32).

Mas nem os habitantes do povoado diferem substancialmente do "selvagem” obrista. Já após a primeira conversa noturna, o caçador se mostra convencido de que o estrangeiro seja um "cara legal” (Prachtkerl) e o médico considera seriamente a emigração para tentar a sorte no Brasil.

Também com respeito ao Brasil, Raabe se mostra informado e crítico. Na coleção de imagens de Kristeller, encontra-se, entre outras gravuras, "a jibóia pendurada na palmeira, na qual o conhecido negro sobe para escorchar-lhe a pele". ${ }^{18}$ Curiosamente, a ilustração faz parte do relato de viagens de John Gabriel Stedman (1796), uma das

${ }^{18}$, ,[...] die am Palmbaum hängende Riesenschlange, an welcher der bekannte Neger hinaufklettert, um ihr die Haut abzuziehen [...]“" (RAABE 1874: 3). 
publicações influentes que denunciaram o abuso de escravos; entre os ilustradores do livro encontrava-se William Blake.

A figura de Agonista ainda pode ser relacionada a outra referência histórica. O coronel não apenas tenta incentivar a emigração de Kristeller e Dorothea. Durante toda a visita no povoado, ele faz propaganda para o "Sao Paradiso" brasileiro. Como enfatizou KROBB (2009: 145), um provável modelo histórico para a personagem é o obrista Georg Anton Aloys von Schäffer, que angariou, no serviço de Dom Pedro I, milhares de alemães de regiões rurais e pobres, sobretudo do Hunsrück e de Mecklenburg, para emigrar ao Brasil. ${ }^{19}$ Este também estudou farmacêutica e medicina, e acabou, após uma vida aventuresca em diversos projetos de colonização, no serviço do primeiro imperador brasileiro. As atividades duvidosas de Schäffer na expedição de Cook, como também registrou KROBB (2009: 147), curiosamente foram relatadas por Adelbert von Chamisso na sua Reise um die Welt, sendo Chamisso o autor do Schlemihl, mais uma história de um botânico pactuário tão simpático e arrependido como Philipp Kristeller.

\section{Novela e objeto simbólico}

Raabe publicou sua narrativa como "Erzählung" [narrativa/conto], a designação menos específica. Na crítica, porém ela é tratada por vários germanistas como "Novelle” [novela] (PARR 2016: 150; GÖTTSCHE 2013: 27, 49) e, de fato ela se adequa bem à descrição da novela na teoria atual (AUST 1993; RATH 2000: 92; KORTEN 2007; FÜLLMANN 2010), mesmo que a existência dessa teoria tenha sido negada por outros críticos. ${ }^{20}$ "Zum wilden Mann" apresenta tanto uma "unerhörte sich ereignete Begebenheit" no sentido de Goethe quanto uma unidade do lugar, do tempo e da ação, culminando numa peripécia que corresponde às ideias de Storm sobre a estrutura dramática da novela. Os acontecimentos se precipitam no prazo de poucos dias, embora nos contos de Raabe haja notoriamente pouca ação (BASSLER 2015b). A concentração da trama e a economia dos recursos, favorecidas

\footnotetext{
${ }^{19}$ A primeira colônia fundada por um grupo organizado por Schäffer foiFrankenthal, na Bahia. A atividade dele nas companhias de emigração se estende de 1824 a 1828. Um estudo aprofundado sobre Schäffer foi publicado no Staden-Jahrbuch por Helmut Andrä (1993: 135-196).

${ }^{20}$ „Novellentheorie ist barer Unsinn. Es gibt keine Theorie der Novelle, auch wenn man, diese bei Reclam als blauen ,Arbeitstext für den Unterricht' kaufen kann“" (HOFFMANN 2008: 63).
} 
pela novela, seguem as exigências do contexto da mídia em que foi publicada: o espaço reservado ao texto literário na revista cultural é limitado - geralmente cerca de quarenta páginas - e a produção de textos curtos atende mais facilmente à periodicidade da publicação do que um romance: este deveria estar pronto para ser publicado em capítulos e não destoar das expectativas do público.

Até a estrutura cíclica da tradição narrativa cultivada desde Boccaccio pode ser encontrada em Raabe de forma modificada: existe uma novela extradiegética, a "Rahmennovelle" apresentada pelo narrador, e, intercalados no modo intradiegético, os dois relatos de Kristeller e Agonista, cada uma sobre uma experiência extraordinária na adolescência. De forma semelhante ao Decamerone e às Unterhaltungen deutscher Ausgewanderten, de Goethe, as novelas intradiegéticas são apresentadas num convívio descontraído e comentadas pelos participantes. No texto de Raabe, diferentemente desses modelos, não se trata de histórias divertidas sobre outras pessoas, mas de episódios biográficos existenciais dos protagonistas.

O texto de Raabe atende, inclusive, à teoria de Paul Heyse sobre o "Dingsymbol", que deveria centralizar o significado do texto, "das Specifische, das die Geschichte von tausend anderen unterscheidet” (HEYSE apud RATH 2000: 245ss). Heyse apresentou suas reflexões no prefácio ao Neuer Deutscher Novellenschatz de 1871, e é muito provável que Raabe tenha lido o primeiro volume dessa coletânea que depois iria publicar outra novela sua, no mesmo ano da publicação de "Zum wilden Mann". ${ }^{21} \mathrm{O}$ primeiro objeto simbólico seria, sem dúvida, a própria farmácia. Oferecendo seu abrigo ao viajante contra a tempestade do início, ela é a materialização do valor do dinheiro doado ou emprestado, lembrando no nome sua origem e o benfeitor duvidosos. No final, a farmácia se transformou em carcaça vazia de uma vida em precariedade.

Mas há outro objeto simbólico que enrola ainda mais fios significativos: a cadeira. A poltrona de honra vazia aparece já nas primeiras páginas, e que ela deva permanecer vazia é o mistério que a primeira história intradiegética resolve. Mas já antes o narrador menciona uma outra "cadeira maldita" na oficina da farmácia: "die böse Bank! Der abgeriebene schlimme Stuhl!" (RAABE 1874: 2ss.). O narrador insinua que até ele e os

\footnotetext{
${ }^{21} \mathrm{O}$ volume 21, que equivale à Série 4, volume 3, de 1874, contém "Das letzte Recht", de Jakob Corvinus, pseudônimo de Raabe. 
leitores teriam sentado nela, aguardando e observando a preparação de seu remédio num estado de ânimo selvagem e ignorante ("wild und dumm" - 1874: 3). Essa observação aparentemente secundária sobre o mal-estar causado simplesmente por se tomar assento numa cadeira preludia a aura negativa que irradia da poltrona de honra.

Pois, desde sua chegada, o coronel Agonista fita a poltrona vazia e, quando sua identidade se revela, recusa-se a se sentar nela, obrigando Dorothea, a dama da casa, a tomar assento ali. Ela acha essa posição "pouco agradável", se sente "violada" e sai da cadeira logo que pode. ${ }^{22}$ Só no dia seguinte, agora já quase um membro da família, Agostin aceita sentar-se na poltrona de honra (1874: 33), onde agora ele fica à vontade para estudar os livros de caixa. Decidida a devolução do empréstimo, o próprio Kristeller pode finalmente sentar na poltrona que ao cabo será adquirida pelo pastor no leilão do inventário. A poltrona simboliza a dívida que deve ser restituída pela pessoa e até o sangue que foi derramado pelos carrascos e que ganhou este dinheiro.

Esse símbolo da dívida entre Philipp e August/Agostin aparece já antes em outra figura: a cadeira de sangue, o "Blutstuhl”, não é apenas o topônimo de uma rocha lúgubre; ela se relaciona também com o cadafalso, o instrumento da execução que, inicialmente, inquieta tanto a consciência de August Mördling. Kristeller descreve a formaçãocomo possível lugar de sacrifícios pagãos.

Es ist ein Labyrinth von Steinklötzen, das einen ziemlich bedeutenden Raum auf der Bergebene einnimmt. Viele der Gruppen führen wunderliche sagenhafte Namen, die höchste ist auf ausgewaschenen Treppenstufen zu erklimmen, und von ihr hat das ganze Geblöck seinen Namen, und in ältester heidnischer Urzeit unseres Volkes hat es denselben als Opferstelle vielleicht mit vollem Recht geführt (RAABE 1874: 15).

É o "Blutstuhl”, onde o "pacto" entre Philipp e August é fechado e, consequentemente, o narrador os chama de "os dois amigos da cadeira de sangue" (RAABE 1874: 29). ${ }^{23}$ E a cadeira como signo metonímico do poder é evocado por Agonista quando este conta das suas atividades maquiavélicas, nas vicissitudes políticas da Améria Latina:

Ja, meine Herrschaften, habe ich da drüben manchen Präsidenten in mancher Republik kommen und gehen sehen, habe selber geholfen, den Excellencen Stühle zuzurücken oder sie ihnen unterm Sitze wegzuziehen, wie's sich gerade schickte (RAABE 1874: 28).

\footnotetext{
22 „Gegen die Gewalt kann ich nicht an, Herr Oberst, aber behaglich sitze ich hier wahrhaftig nicht, und in die Wirthschaft muß ich auch jeden Augenblick hinaus“ (RAABE 1874: 23).

23 "[...] die beiden Freunde vom Blutstuhl umarmten sich noch einmal [...]"(RAABE 1874: 29).
} 
Galle, H. - Selvagens e pactos demoníacos

Numa sequência histórica, o Blutstuhl é primeiro o lugar do sacrifício da religão pagã, substituído pela violência exercida em nome do poder absoluto e, afinal, pelo crédito que movimenta os negócios do mundo capitalista. A aura do sinistro do mal e do diabólico se relaciona às instituições simbolizadas, mas também à própria poltrona, e é mais uma ironia que ela seja adquirida pelo pastor.

A serenidade do protagonista Kristeller diante de sua miséria parece grotesca, e sua irmã, com sua queixa, apresenta uma reação mais coerente. Na perspectiva materialista, a situação dos dois é mais que lamentável. O que lhes resta é a memória de tempos mais felizes. Philipp Kristeller, porém, está, pela primeira vez, livre da sua dívida. Na interpretação schopenhaueriana de Fauth (2007: 110), ele, como outros protagonistas de Raabe, é um "Weltüberwinder" que se desprendeu de "toda sua propriedade terrestre" para enfrentar o nada. Para Raabe (como para os outros autores do realismo), esta forma de renúncia absoluta parece ser a ultima ratio diante um mundo errado.

\section{Brasil e Alemanha}

"Zum wilden Mann" foi escrito por um autor com um amplo horizonte intelectual e uma grande capacidade criativa, localizado em sua cultura e seu tempo. A novela reflete esta localização: o mundo projetado pode ser compreendido da melhor forma por um público que compartilha o posicionamento e o conhecimento do autor, ou seja, seus compatriotas e contemporâneos. Isso não exclui a possibilidade de que seu horizonte possa ser reconstruído e que o conhecimento da nossa posterioridade possa complementar a compreensão do texto substancialmente. Mas, em primeiro lugar, o texto reflete as preocupações do alemão no boom e na depressão dos anos 1870. O Brasil de Raabe é um Brasil de segunda mão, um Brasil filtrado pelos discursos da época. Sendo um autor consciente, ele faz um uso prudente desses elementos discursivos. Os elementos brasileiros que compõem a narrativa são escolhidos e construídos em função do retrato do mundo, centrado na Alemanha que Raabe imaginou. O texto é interessante, por causa de sua visão do Harz, uma metonímia da Alemanha, da Europa, e de forma muito indireta também do Brasil. Os processos históricos que aparecem de forma simbólica - a mercantilização das relações humanas, a liquidação da cultura e a marginalização de atitudes éticas - 
correspondem a preocupações de observadores críticos da época de Raabe e podem ser constatados, tendencialmente, até o nosso presente.

\section{Referências bibliográficas}

Aust, Hugo. Novelle. In: KILLY, Walter (org.) Literaturlexikon, vol.14. München: Bertelsmann 1993. 170-175.

BASSLER, Moritz. Deutsche Erzählprosa 1850-1950. Eine Geschichte literarischer Verfahren. Berlin: Erich Schmidt, 2015a.

BASSLER, Moritz. Figurationen der Entsagung. In: PARR, Rolf; BERTSCHIK, Julia (org.). Jahrbuch der Wilhelm-Raabe-Gesellschaft, 2010. p. 63-81.

BASSLER, Moritz. Zum wilden Mann. Frankfurter Allgemeine Zeitung, 15 Aug. 2015b.

DETERING, Heinrich. Theodizee und Erzählverfahren. Narrative Experimente mit religiösen Modellen im Werk Wilhelm Raabes. Göttingen: Vandenhoeck \& Ruprecht, 1990.

DOBSTADT, Michael. »unter das schützende Dach dieser neuen Geschichte zu gelangen«. Wilhelm Raabes Erzählung »Zum wilden Mann« als Versuch, der Moderne literarisch beizukommen. In: GÖTTSCHE, Dirk; SCHNEIDER, Ulf-Michael (org.). Signaturen realistischen Erzählens im Werk Wilhelm Raabes. Würzburg: Königshausen \& Neumann, 2010. p. 19-39.

DunKER, Axel. First Contact and Déjà Vu: The Return of Agostin Agonista in Raabe's Zum wilden Mann. In: GÖTTSCHE, Dirk; KROBB, Florian (org.). Wilhelm Raabe. Leeds: Legenda, 2009. p. $52-60$.

FAUTH, Søren. Der metaphysische Realist. Zur Schopenhauer-Rezeption in Wilhelm Raabes Spätwerk. Göttingen: Wallstein, 2007.

FÜLLMANN, Rolf: Einführung in die Novelle, Darmstadt: Wissenschaftliche Buchgesellschaft, 2010.

GÖTTSCHE, Dirk. »Tom Jensen war in Indien«. Die Verknüpfung europäischer und außereuropäischer Welten in der Literatur des Realismus. In: BERBIG, Roland (org.).Metropole, Provinz und Welt. Berlin [u.a.]: De Gruyter, 2013. p. 17-52.

GÖTTSCHE, Dirk. Der koloniale „Zusammenhang der Dinge“ in der deutschen Provinz. Wilhelm Raabe in postkolonialer Sicht. Jahrbuch der Wilhelm-Raabe-Gesellschaft, 2005. p. 53-73.

GöTTSCHE, Dirk. Raabe in postkolonialer Sicht. In: GöTTSCHE, Dirk Göttsche Dirk; KROBB, Florian Krobb Florian; PARR, Rolf Parr Rolf (org.).Raabe-Handbuch. Stuttgart: J. B. Metzler, 2016. p. 293-298.

HofFMAnN, Volker. Zum Wilden Mann. Jahrbuch der deutschen Schillergesellschaft, v. 30, p. 472-492, 1986.

KoRTEN, Lars. Novelle. In: SCHWEIKLE, Günther, et al. (orgs.) Metzler Literatur Lexikon. Stuttgart, Weimar: Metzler 2007. 547-548.

KroBB, Florian. Erkundungen im Überseeischen. Wilhelm Raabe und die Füllung der Welt. Würzburg: Königshausen \& Neumann, 2009.

KrobB, Florian. Übersetzungen. In: GöTTSCHE, Dirk Göttsche Dirk; KroBB, Florian Krobb Florian; PARR, Rolf Parr Rolf (org.).Raabe-Handbuch. Stuttgart: J. B. Metzler, 2016. p. 3840.

LuKACS, Georg. Deutsche Realisten des 19. Jahrhunderts, Bern: Francke, 1951.

OPPERMANN, Hans. Wilhelm Raabe. Rowohlt, Reinbek bei Hamburg 1970.

Pandaemonium, São Paulo, v. 20, n. 32, set.-dez. 2017, p. 66-83 
OSTERHAMMEL, Jürgen: Die Verwandlung der Welt. Eine Geschichte des 19. Jahrhunderts, München: Beck, 2009.

OTT, Norbert. Wildleute. In: Lexikon des Mittelalters. München: Dt. Taschenbuch, 2002. v. 9: Werla bis Zypresse Register, p. 120-121.

PARR, Rolf. Materielle und semantische Tauschprozesse in Wilhelm Raabes Erzählung »Zum wilden Mann«: materiell und semantisch. In: MEIN, Georg; SCHÖSSLER, Franziska (org.).Tauschprozesse. Bielefeld: [s.n.], transcript 2005. p. 275-290.

PARR, Rolf. Zum Wilden Mann. In: GÖTTSCHE, Dirk Göttsche Dirk; KROBB, Florian Krobb Florian; PARR, Rolf Parr Rolf (org.).Raabe-Handbuch. Stuttgart: J. B. Metzler, 2016. p. 149-157.

RAABE, Wilhelm. Meister Autor. Zum Wilden Mann. Höxter und Corvey. Eulenpfingsten. Bearbeitet von Gerhard Meyer und Hans Butzmann. In: HoPPE, Karl et al. (org.).WilhelmRaabe:Sämtliche Werke. Göttingen: Vandenhoeck \& Ruprecht, 1973. v. 11. Disponível em: <http://daten.digitalesammlungen.de/ db/0004/bsb00044630/images/index.html?id=00044630\&groesser $=150 \%$ $\underline{\text { ffip }=193.174 .98 .30 \& \text { no }=\& \text { seite }=5>}$ > Acesso em: 21 jun. 2017.

RAABE, Wilhelm. Zum Wilden Mann. Westermanns Monatshefte, v. 19, p. 1-45, Apr. 1874.

RAABE, Wilhelm: Zum wilden Mann. Eine Erzählung. Ed. de Axel Dunker. Stuttgart: Reclam, 2006.

RATH, Wolfgang: Die Novelle. Konzept und Geschichte, Göttingen: Vandenhoeck \& Ruprecht, 2000.

STEDMAN, John. Narrative of a five years' expedition against the revolted Negroes of Surinam, London: J. Johnson and J. Edwards, 1796.

VILLAS BÔAS, Luciana. Os selvagens de Nuremberg e o seu lamento pela imprensa de 1545. Revista de Letras, Curitiba, v. 24, n. 49, p. 131-151, 2014.

WÜNSCH, Marianne. Moderne. In: GöTtSCHE, Dirk; KROBB, Florian; PARR, Rolf (org.).RaabeHandbuch. Stuttgart: J. B. Metzler, 2016. p. 366-369.

Recebido em 04/06/2017 Aceito em 19/06/2017 